\title{
НЕПРЕДСКАЗУЕМОЕ
}

\author{
И.В. Матюхин
}

\section{ПОЛИГРАФОЛОГИЧЕСКОЕ ОБСЛЕДОВАНИЕ КЛИЕНТОВ С ПАНИЧЕСКИМИ АТАКАМИ}

\begin{abstract}
Аннотация. В данной работе представлены процесс и результаты оригинального психологического исследования, сформированного на запрос из клинической среды на фиксацию наличия действительных объективных изменений психофизиологических параметров клиентов с тревожным расстройством класса панических атак при наличии субъективно отмеченных дискомфортных психических ощущений. Исследование проводилось специальным, прикладным, психофизиологическим методом с применением технического средства компьютерного профиля посредством полиграфологической комплексной регистрации параметров вегетативных реакций испытуемых. Смоделирована ситуация возникновения тревожного расстройства и получены результаты двух доминантных типов симпатического реагирования со специфическими профилями изменений информативных признаков Представлены подробно значимые колебания индикаторных психофизиологических параметров в структуре реакций испытуемых в кардио-канале, пневмо-канале, канале кожно-гальванических реакций и плетизмографическом информативном канале. Зафиксировано отчётливое изменение объективных психофизиологических характеристик, протекающих синхронно переживанию дискомфортных психических ощущений, информативно дополняющих клиническую картину возникновения и протекания тревожного расстройства класса панических атак на субъективном и на объективном уровнях. Представлены комплексные типологии реакций вегетативного реагирования в структуре психофизиологического исследования, проводимого по клиническому запросу.
\end{abstract}

Ключевые слова: психофизиология, паническая атака, запрос, симптом, тревога, полиграф, измерение, полиграмма, стимулы, реакции.

Review. In his article Matyukhin describes the process and results of an original psychological test that was developed as a response to medics' request to analyze whether there are objective changes of psychophysiological parameters demonstrated by clients with the anxiety disorder and panic attacks when they subjectively experience uncomfortable sensations. The research was conducted using the special applied psychophysiological method and the technology of creating a computer-based profile through polygraphic registration of vegetative reactions demonstrated by repondents. The researcher has built the situation model of manifestation of the anxiety disorder and has described the two dominating types of sympathetic nervous system reactions as well as specific profiles of changes in their indicators. The results of the research show statisfically significant changes in psychophysiological indicators, in particular, cardio channel, pneumo channel, galvanic skin reaction channel and plethysmographic information channel. Thus, the research has allowed to discover distinct changes in objective psychophysiological parameters that are synchronized with uncomfortable sensations and thus complete the clinical picture of the manifestation and unfolding of a panic attack both at the subjective and objective levels. The researcher also provides classifications of different types of vegetative reactions as part of the psychophysiological research conducted upon the clinical request.

Keywords: measurement, polygraph, anxiety, symptom, request, panic attack, psychophysiology, polygrams, incentives, reactions.

\section{Введение}

Необходимо отметить, что практически отсутствуют исследования, позволяющие судить о влиянии преморбидных характеристик личности на клиническое оформление панических атак, не обозначен предпочтительный личностный тип для их формирования. Одной из наиболее вероят- ных причин появления панических расстройств является выраженный уровень личностной тревоги, однако число публикаций по этой проблеме ограничено [1].

К настоящему времени имеются лишь некоторые данные по клиническим особенностям, дифференциации панических атак, неполно изучены сопутствующие аффективные и вегетативные 


\section{Непредсказуемое}

проявления, а также соматическая дисфункция. Существующая противоречивость в оценке панических расстройств, недостаточная разработанность таких серьёзных аспектов проблемы, как семиология, условия формирования, реабилитация, свидетельствуют о её актуальности и целесообразности комплексного исследования или следования структурной составляющей природы данного феномена. Так как данная проблема из сферы психиатрии и клинической психологии, то необходимо опираться на фундаментальный нейробиологический и психофизиологический базис, который представлен перечисленными науками. В настоящее время существуют инструментальные специальные психофизиологические исследования, которые позволяют зафиксировать физические, химические, нейрофизиологические и другие особенности материальных субстратов мозговых структур, значимо влияющих на функционирование психической жизни индивида. Среди инструментальных средств психофизиологической диагностики можно перечислить такие технические средства как электроэнцефалография (ЭЭГ), полиграф, магнитоэнцефалография, магнито-резонансная томография, айтрекинг, транскраниальная магнитная стимуляция и другие. Среди перечисленных средств некоторые уже использовались как средство психофизиологической диагностики особенностей клиентов с паническими атаками. Проводилось исследование по частотно - мощностной характеристике ЭЭГ у клиентов с респираторными паническими атаками. Сравнительный анализ частотно-мощностных характеристик электроэнцефалографии в покое и после трехминутной гипервентиляционной нагрузки показал, что у больных с респираторными паническими атаками (в отличие от пациентов с типичной структурой атак и у здоровых испытуемых) отмечалось увеличение мощности медленноволнового спектра с гиперсинхронизацией $\theta$ - ритма в височно-центральном регионе [2].

\section{Постановка проблемы}

Представляется целесообразным продолжить данную линию психофизиологических исследований с применением технического средства из ранее отмеченной группы.

Полиграф - это техническое средство, обеспечивающее измерение психофизиологических параметров, регистратор вегетативных реакций, выявляющий эмоциональную значимость по фактуре изменения психофизиологических реакций на предъявляемые стимулы. Это неинвазивный, специальный, психофизиологический метод исследования, который журналисты назвали «детектором лжи», что не очень верно отражает функциональную сущность упомянутого технического средства. Вся полиграфология началась с работ А.Р. Лурия, который интенсивно разрабатывал основные постулаты психофизиологии и нейропсихологии, а развивалась полиграфология более интенсивно в США. В России активное изучение полиграфологии началось с 1975 г., когда была открыта секретная лаборатория КГБ, и изучением психофизиологических основ и разработкой полиграфа занимались такие личности как Азаров, Холодный, Федоренко, Коровин, Сошников.

В настоящее время полиграфология активно используется не только в криминалистике, но и в психодиагностике, являясь дополнительным инструментальным методом сбора необходимых в зависимости от запроса данных. Среди полиграфологов существуют собственные практические психодиагностические наработки, эффективно помогающие решать комплексные и системные задачи прикладного характера. Некоторые специалисты в России активно занимаются деятельностью по оперативной психодиагностике личности в ходе психофизиологического исследований с применением полиграфа [3].

Из клинической практики часто поступают запросы на обработку и описание вегетативных реакций организма при предъявлении специфических стимулов при моделировании ситуации изучаемого явления. Клинические психологи в настоящее время среди тревожных расстройств самым распространенным называют панические атаки, которые могут присутствовать в структуре как панического расстройства, так и в структуре других психических расстройств вроде депрессии, обсессивно-компульсивного расстройства, генерализованного тревожного расстройства, социофобии или дебюта шизофрении, биполярного аффективного расстройства, а так же манифеста личностного расстройства [4].

Диагноз панических атак из психиатрии и клинической психологии часто переходит в среду неврологов, где данное расстройство рассматривают как нейро-циркуляторную дистонию или вегето - сосудистую дистонию, спрос на лечение которых сейчас очень велик. 


\section{Психология и психотехника 9(84) • 2015}

Клинические психологи отмечают, что у клиентов с паническими атаками присутствует нейробиологическая разбалансировка, которая приводит к переживанию дисфункциональных, психологически дискомфортных ощущений, однако переживаемых не самих по себе, а возникающих вследствие воздействия на нарушенный центральный баланс нервной системы запускающего социального фактора [5].

Анализ литературы Б.Д. Карвасарского, Г.И. Каплана, М.Я. Киссина показал, что при наступлении психовегетативного криза мы можем наблюдать дезадаптивное поведение у индивида в рассматриваемом нами пространстве количественного континуума, т.е., градуируя оценку поведения от малого количества до сравнительно большого. Структурные фрагменты перечисленных выше источников библиографии разъясняют, что разбалансированная нейробиологическая субстанция является фундаментом, на основе которого, социальный фактор играет роль пускового толчка, запускающий механизм поведенческой цепочки [6], представленной следующими образом:

- психическое отражение;

- негативный симптом;

- психическая дезориентация;

- физиологическое подкрепление дезориентации;

- $\quad$ усиление симптоматики;

- вынужденное дезадаптивное поведение.

Как мы видим, социальная ситуация через дискомфортные психофизиологические симптомы приводит к вынужденному дезадаптивному поведению, частыми проявлениями которого являются агрессия и избегание [7].

Активность дискомфортных дискомфортных симптомов напрямую связана на физиологическом уровне с перегрузкой и частичной компенсаторной дисфункциональностью симпатической нервной системы, однако динамика данного феномена проявляется по-разному.

Т.Д. МакГлинн выделяет 2 остро-доминирующих и значимых типа симптоматических реакций у клиентов во время наступления вегетативного криза [8]:

1. физиологическое ощущение притока крови, волна жара;

2. физиологическое ощущение сбивчивости дыхания, остановки дыхания, удушья, резкого истощения.
Т.Д. МакГлинн поясняет, что вышеперечисленные клинические симптомы отмечаются в субъективном пространстве индивидов, а реакции описываются психологическим языком, который часто не коррелирует с объективной картиной наличия перечисляемых физиологических временных дисфункциональностей [8]. Учитывая сказанное, возникла потребность в целевой проверке профиля вегетативных реакций некоторых испытуемых на действительное наличие объективных изменений, присутствующих в психофизиологической характеристике картины течения или ожидания вегетативного криза.

Цель исследования - проверить, имеется ли наличие объективных, физиологических коррелятов психических дискомфортных ощущений, наблюдаемых в клинической картине панических атак. В задачи исследования входит следующее:

1. Смоделировать социальную ситуацию возникновения панических атак.

2. Идентифицировать и зафиксировать объективные изменения психофизиологических параметров посредством применения полиграфа.

3. Выделить основные психофизиологические типы реагирования по результатам обследования на полиграфе.

Главная гипотеза исследования (H0) - наличие субъективных дискомфортных психических ощущений в картине течения панических атак сопровождается отчетливыми объективными изменениями психофизиологических параметров в виде акцентуированной активности вегетативной нервной системы. Конкурирующая гипотеза (Н1) - наличие субъективных дискомфортных психических ощущений в картине течения панических атак не сопровождается объективными изменениями психофизиологических параметров, а представлено только субъективно в тревожно-мнительном профиле психического восприятия.

\section{Методика исследования}

Метод проведения специального прикладного психофизиологического исследования на базе полиграфа - технического средства, являющегося валидным и надежным психодиагностическим инструментом и комплексным регистратором вегетативных реакций. Аппаратурой, обеспечивающей проведение технического аспекта исследования, является цифровой полиграф фирмы «Поликони- 


\section{Непредсказуемое}

ус», марки «Диана-01», разработчик А.П. Сошников [3]. Программное обеспечение полиграфа разработано для использования в среде Windows XP. Обеспечивает информативность кардиоканала, пневмоканала, канала кожно - гальванических реакций, а так же тахограмическую регистрацию. Ведущий узловой блок - приёмник сигналов, являющийся дешифратором поступающей с датчиков информации и вывода в стандартизованном виде на экран персонального компьютера. На кардиоканал приходится два датчика: первый регистрирует артериальное давление, второй (плетизмографический) сокращение периферических сосудов. Пневмоканал также обеспечен двумя датчиками: первый регистрирует верхнее (грудное) дыхание, второй регистрирует нижнее (диафрагмальное) дыхание. Канал кожно - гальванических реакций представлен одним датчиком. Аппаратура полиграфа (приёмник, датчики с проводящими шнурами, манжета артериального давления) в собранном (транспортировочном) виде является рабочим багажом практического полиграфолога. Выходные сигналы фиксируемых психофизиологических параметров отражаются в виде стандартизованной полиграммы, на которой процессуально записывается динамика протекания регистрируемых вегетативных реакций. Пример полиграммы представлен на рисунке 1.

Статистическим методом обработки данных является метод проверки статистических гипотез (главной Н0 и конкурирующей Н1).

\section{Результаты и их обсуждение}

Характеристики выборки - 29 добровольцев в возрасте от 24 до 42 лет. Из них 13 представителей женского пола и 16 представителей мужского пола. У всех испытуемых был диагностирован минимум один приступ панической атаки. Согласие на проведение исследования было дано испытуемыми после предварительного ознакомления со всей процедурой, целями и задачами исследования. Проверка на полиграфе является стрессогенной ситуацией, так как техническое средство популяризовано как «детектор лжи», в непогрешимости выявления значимой информации никто не сомневается. Сам факт полиграфологической проверки априори предполагает наличие в психической жизни индивида утаиваемой информации, которую необходимо актуализировать при помощи релевантных стимулов и представить в выходной чита-

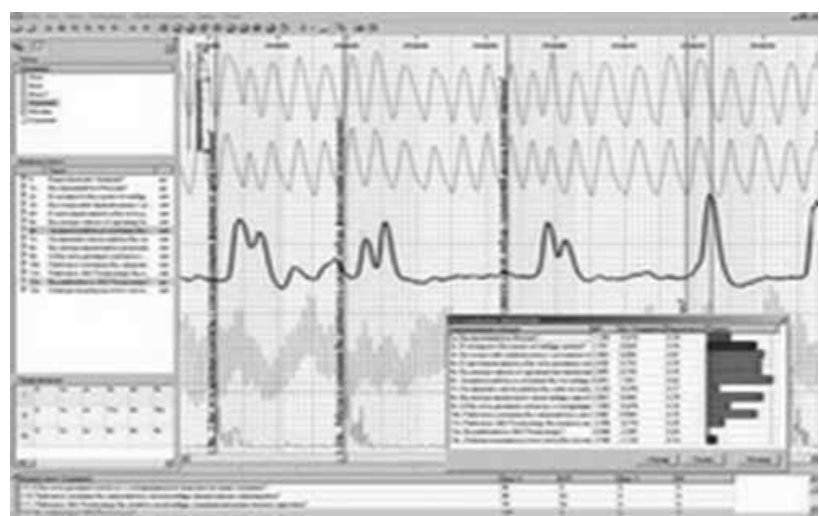

Рисунок 1. Образец полиграммы.

емой форме. При моделировании социальной ситуации, запускающей картину течения панических атак, полиграфологическая проверка несет в себе много дискомфортных, тревожных, ситуативных компонентов, которые так же отражены в техническом аспекте самой проверки. Это предтестовая (скрининг) беседа, подключение и настраивание датчиков, наличие которых может способствовать возникновению волнения ожидания, особенно у клиентов данной группы, имеющих в анамнезе тревожное поведение. Т.А. Нелюбова утверждает в работе об эмоционально-вегетативных кризах, что паническая атака всегда возникает в социальной ситуации, когда в текущей обстановке присутствует более 2 человек, а также обеспечивается объективное или субъективно-мнимое внимание на индивида [9].

Ю.Л. Нуллер повествует о том, что возникновение панических атак осуществляется при наличии ситуации ожидания в психическом восприятии индивида [10].

Исходя из вышесказанного отметим, что обстановка моделирования социальной ситуации возникновения панической атаки должна быть предсказуемой и отвечать критерию тревожного ожидания. В нашем случае непосредственной процедуре обследования на полиграфе предшествовала предтестовая беседа, которую в среде профессиональных полиграфологов называют скринингом. Но скрининговая беседа направлена на чтение ярких психологических характеристик индивида и выявления его слабых сторон, так как запрос на полиграфологическое обследование стандартно осуществляется в других формах и направлениях. В нашем исследовании предтестовая беседа была другого характера и учитывала клинический 
аспект сложившегося запроса. Ввиду того, что в числе наших испытуемых люди с тревожным профилем, то предстестовая беседа носила характер уточняющего ознакомления с процедурой обследования, его целями и задачами, обоснования безопасности и стабилизации психического состояния испытуемых, чтобы не зафиксировалось раннее избегающее поведение или его аспекты, которые могут наблюдаться в заданных условиях. Основные этапы предтестовой беседы:

- знакомство, конгруэнтный контакт;

- обоснование безопасности и конфиденциальности исследования;

- $\quad$ поэтапное напоминание процедуры;

- $\quad$ плавное течение диалога, способствующее позитивное принятие;

- поиск точки доверительного соприкосновения;

- $\quad$ эмпатичное слушание и не директивное течение беседы;

- постепенное завершение предтестовой беседы.

Далее следовала непосредственная процедура обследования на полиграфе, включающая следующие этапы:

- подключение датчиков;

- апробация датчиков, запись фоновой полиграммы;

- $\quad$ стимуляционно-адаптационный тест.

После стимуляционно-адаптационного теста процедура исследования завершалась. Учитывая тревожный профиль испытуемых не целесообразно проводить конкретно-целевое тематическое тестирование с дополнительными, уточняющими стимульными методиками, так как из-за монотонности, напряжённости и продолжительности процедуры обследования возможно травмирование испытуемых. Запись фоновой полиграммы включала в себя наблюдение за психофизиологическими параметрами во время теста следующего содержания:

Вас зовут?

- Саша;

- Маша;

- Даша;

- Петя;

- Имя испытуемого;

- Виктор.

T.e. тест во время записи фоновой полиграммы включал 5 нейтральных вопросов и 1 проверочный. Тест предъявлялся 5 раз, каждый раз меняя местами вопросы. Стимуляционно-адаптационный тест с известным значимым включал в себя те же вопросы, что и при записи фоновой полиграммы по 5 предъявлений теста. После второго предъявления стимуляционно-адаптационного теста в комнату, где осуществлялась проверка, и присутствовали только испытуемый и полиграфолог, заходили другие люди, каждый из которых так же принимал участие в данном исследование. Вошедшие участники садились в стороне и наблюдали за процедурой. Тем самым обеспечивалось более реальноподобное моделирование социальной ситуации, и одновременно каждый из испытуемых мог «примерно» наблюдать за собой со стороны. После проведения всей процедуры исследования были просмотрены полиграммы и проанализированы на предмет объективных изменений психофизиологических параметров. Несмотря на то, что 12 человек покинули кабинет во время осуществления процедуры исследования, объективные данные были зафиксированы, так как начало избегающего поведения индивида появлялось в среднем через 3 минуты после изменения социальной насыщенности обстановки обследования. Стоит отметить, что во всех 29 случаях были зафиксированы резкие изменения психофизиологических параметров, что подтверждает отражение психического дискомфорта и на психофизиологическом уровне, $\mathrm{a}$, следовательно, подтверждение нашей гипотезы исследования. Характер данных информативных изменений был очевидным, анализируя картину которых И.В. Матюхин выделил 2 типа:

a) «Тип А»- у людей, относящихся к данному типу наблюдались следующие информативные изменения:

- всплеск кожно - гальванической реакции;

- изменение дыхательных параметрических данных (увеличение частоты верхнего дыхания, уменьшение объема верхнего дыхания).

Всплеск кожно - гальванического рефлекса происходил на величину большую прежней в 1,5 раза так, как показано на рисунке 2.

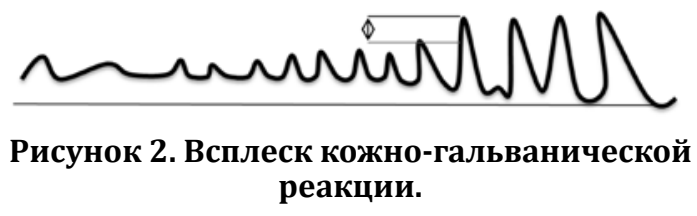

Изменение дыхания заключалось в разной модификации течения изменения, однако, самым частым наблюдаемым признаком являлось увели- 


\section{Непредсказуемое}

чение частоты верхнего дыхания, изображённое на рисунке 3 .

\section{montWHWH}

\section{Рисунок 3. Увеличение частоты} верхнего дыхания.

б) «Тип Б» - у испытуемых данного типа в симпатическом реагировании наблюдались следующие изменения:

- всплеск кожно-гальванической реакции;

- подъём артериального давления;

- уменьшение амплитуды в плетизмографическом канале.

В группе испытуемых типа «Б» среди информативных признаков к всплеску кожно - гальванической реакции добавился подъём артериального давления на величину в среднем в 2 раза больше от текущего, изображённый на рисунке 4.

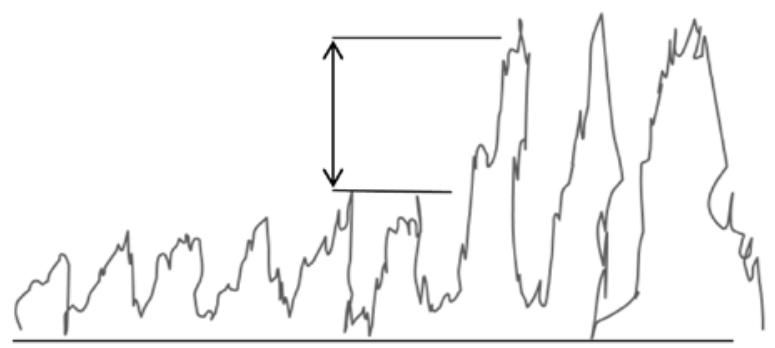

Рисунок 4. Подъём артериального давления.

Так же у испытуемых типа «Б» среди значимых информативных признаков зафиксировано уменьшение амплитуды в плетизмографическом канале, изображённое на рисунке 5 .

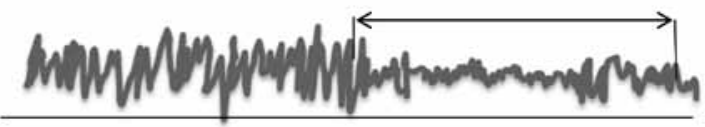

Рисунок 5. Уменьшение амплитуды в плетизмографическом канале.

В материалах обработки математической статистикой отметим, что имеется независимая выборка $(\mathrm{x} 1, \ldots \mathrm{xn}) \sim \mathrm{N}(\mu, 1)$ из нормального распределения, где $\mu$ - неизвестный параметр. Тогда H0: $\{\mu=\mu 0\}$, где $\mu 0$ - фиксированная константа, является простой гипотезой, а конкурирующая с ней H1: $\{\mu>\mu 0\}$ - сложной, уровень значимости $\mathrm{a}=0,01$, критическое число уровня значимости К1 $=0,05$, критическое число уровня значимости К2 $=0,01$.
Мы получили следующую эмпирическую оценку: tэ $\approx 2,798$. Находим по статистической таблице («Критические точки распределения Стьюдента») для степеней свободы $\mathrm{df}=7$ критические значения. $\mathrm{t} 1=2,36$ (для уровня значимости $\alpha \leq 0,05$ ), $\mathrm{t} 2=3,50$ (для уровня значимости $\alpha \leq 0,01$ ). Отсюда имеем неравенство: $2,36<2,798<3,50$. Т.е. эмпирическое значение лежит в «зоне неопределённости». Можно считать полученную статистическую оценку достоверной на уровне значимости 0,01. В этом случае принимается гипотеза Н0, т.е. наша главная гипотеза подтвердилась.

\section{Выводы}

1. В клинической картине протекания тревожного расстройства класса панических атак при помощи прикладного, психофизиологического метода на основе полиграфа зафиксированы значимые изменения объективных психофизиологических индикаций, протекающих синхронно переживанию дискомфортных, субъективных, психических ощущений.

2. Выделены два доминантных типа симпатического реагирования на предъявляемые стимулы: тип «А» - со значимыми колебаниями в каналах кожно - гальванической реакции и верхнего дыхания и тип «Б»- со значимыми колебаниями в каналах кожно - гальванической реакции, артериального давления и плетизмографии.

3. Из всех 29 испытуемых к первому типу симпатического реагирования относится 11 человек, а ко второму типу симпатического реагирования относится 18 человек, долевое соотношение количественных данных наглядно представлено на рисунке 6.

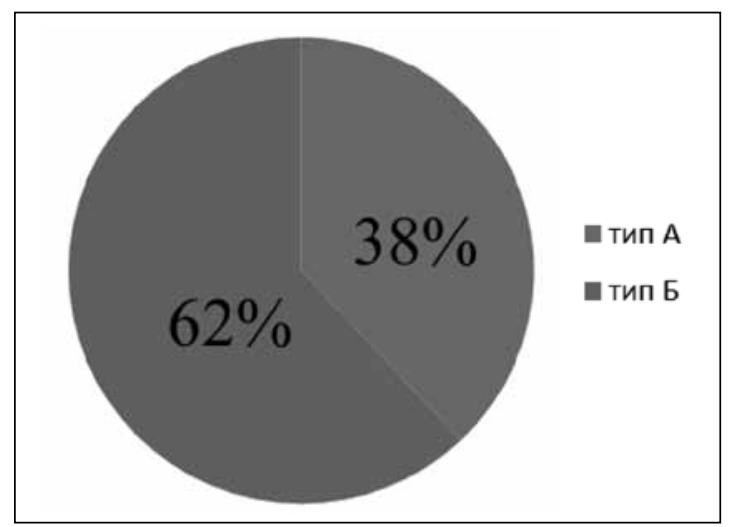

Рисунок 6. Диаграмма процентно - долевого соотношения типа «А» к типу «Б». 


\section{Психология и психотехника 9(84) • 2015}

Из рисунка 6 мы видим, что доля людей из всей выборки исследования, относящихся к симпатическому реагированию типа «А», составляет $62 \%$ (11 человек), а доля людей, относящихся к симпатическому реагированию типа «Б», составляет 38\% (18 человек).

\section{Заключение}

В результате прикладного психофизиологического исследования клиентов с паническими атаками выполнены все задачи, сформированные по запросу из клинической среды на проведение исследования клиентов с тревожным профилем класса панических атак. Во всех 29 случаях зафиксированы объективные изменения психофизиологических параметров во время течения дискомфортных психических симптомов, что даёт дополнительные данные для построения более полной клинической картины тревожного расстройства вида панических атак, продолжая линию применения специальных психофизиологических методов в общем пространстве психологических систем, выявляя объективные индикации, коррелирующие с субъективными характеристиками. Данный вид исследований позволяет своевременно отвечать на психодиагностический запрос из любой отрасли современной психологии, где необходимо психофизиологическое отражение естественно научных основ рассматриваемого объекта, и формировать по результатам исследования информативную базу, расширяющую и углубляющую научный взгляд на проблематику, определяя более полную картину явления.

\section{Список литературы:}

1. Вознесенская Т.Г., Синячкин М.С. Неоднородность панических атак (нейрофизиологическое исследование) // Тревога и обсессии. М., 1998. С. 326-327.

2. Романенко Е.К. Респираторные панические атаки: клинические, нейрофизиологические и психологические особенности: Автореф. дис. ... д-ра психол. наук. М., 2012. 47 с.

3. Венерина О.Г., Сошников А.П. Оперативная психодиагностика личности в ходе психофизиологического исследования с применением полиграфа // Вестник МГГУ им. М.А. Шолохова. 2005. № 7. С. 10-12.

4. Волошин В.М., Сперанская О.И., Ерохина СВ. Структура и терапевтическая динамика психовегетативных нарушений при соматоформной вегетативной дисфункции // XII съезд психиатров России, 1-4 ноября 1995 г. (материалы съезда). М., 1995. С. 193-196.

5. Карвасарский Б.Д. Неврозы. М.: Медицина, 1985.

6. Киссин М.Я. Психовегетативные кризы (систематика, клиника, нозология) // Актуальные вопросы клинической и социальной психиатрии. СПб.: Санкт-Петербургская городская психиатрическая больница № 1 им. П.П. Кащенко, 1999. С. 309-324.

7. Кредитор Д. Паническое расстройство и коморбидные состояния // Тревога и обсессии. М., 1998. С. 66-75.

8. Мак Глинн Т.Д., Меткалф Г.Л. Диагностика и лечение тревожных расстройств (Руководство для врачей) / Пер. с англ. American Psychiatric Press, 1989. 119 c.

9. Нелюбова Т.А. Эмоционально-вегетативные кризы и личностные реакции при них в клинике пограничных состояний: Автореф. дис. ... канд. мед. наук. Фрунзе, 1976. 19 с.

10. Нуллер Ю.Л. Тревога и её терапия // Психиатрия и психофармакотерапия. 2002. Т. 4. № 2. С. 46-48.

11. Комиссарова Я.В. Методические аспекты психофизиологическогоисследования с применением полиграфа // Российский судья. 2006. № 2.

12. Молчанов А.Ю. Общая теория полиграфных проверок. М., 2012.

13. Молчанов А.Ю. Атлас полиграмм. М.: Индиго, 2007.

14. Пиз А. Язык жестов / Пер. с англ. Воронеж: НПО «МОДЭК, 1992.

15. Филонов Л.Б. Психологические способы выявления скрываемого обстоятельства. М., 1979.

16. Холодный Ю.И. Опрос с использованием полиграфа и его естественно-научные основы // Вестник криминалистики / Отв. ред. А.Г. Филиппов. Вып. 1(13) и 2(14). М., 2005.

17. Ц Целибеев Б.А. Психические нарушения при соматических заболеваниях. М.: Медицина, 1972. 279 с.

18. Юнг К.Ю. Психологические типы. М.: Университетская книга, АСТ, 1998. 716 с.

19. Юров И.Е. Панические расстройства у лиц молодого возраста: клинико-психол., гемодинам. и патобиохим. аспекты: Автореф. дис. ... канд. мед. наук. М., 2000.

20. Ялов А.М. Копинг-поведение и механизмы психологической защиты у больных неврозами // Обозрение психиатрии и мед. психологии им. В.М. Бехтерева. 1996. № 3-4. С. 35-38.

\section{References (transliteration):}

1. Voznesenskaya T.G., Sinyachkin M.S. Neodnorodnost' panicheskikh atak (neirofiziologicheskoe issledovanie) // Trevoga i obsessii. M., 1998. S. 326-327. 


\section{Непредсказуемое}

2. Romanenko E.K. Respiratornye panicheskie ataki: klinicheskie, neirofiziologicheskie i psikhologicheskie osobennosti: Avtoref. dis. ... d-ra psikhol. nauk. M., 2012. 47 s.

3. Venerina O.G., Soshnikov A.P. Operativnaya psikhodiagnostika lichnosti v khode psikhofiziologicheskogo issledovaniya s primeneniem poligrafa // Vestnik MGGU im. M.A. Sholokhova. 2005. № 7. S. 10-12.

4. Voloshin V.M., Speranskaya O.I., Erokhina SV. Struktura i terapevticheskaya dinamika psikhovegetativnykh narushenii pri somatoformnoi vegetativnoi disfunktsii // XII s»ezd psikhiatrov Rossii, 1-4 noyabrya 1995 g. (materialy s»ezda). M., 1995. S. 193-196.

5. Karvasarskii B.D. Nevrozy. M.: Meditsina, 1985.

6. Kissin M.Ya. Psikhovegetativnye krizy (sistematika, klinika, nozologiya) // Aktual'nye voprosy klinicheskoi i sotsial'noi psikhiatrii. SPb.: Sankt-Peterburgskaya gorodskaya psikhiatricheskaya bol'nitsa № 1 im. P.P. Kashchenko, 1999. S. $309-324$.

7. Kreditor D. Panicheskoe rasstroistvo i komorbidnye sostoyaniya // Trevoga i obsessii. M., 1998. S. 66-75.

8. Mak Glinn T.D., Metkalf G.L. Diagnostika i lechenie trevozhnykh rasstroistv (Rukovodstvo dlya vrachei) / Per. s angl. American Psychiatric Press, 1989. 119 s.

9. Nelyubova T.A. Emotsional'no-vegetativnye krizy i lichnostnye reaktsii pri nikh v klinike pogranichnykh sostoyanii: Avtoref. dis. ... kand. med. nauk. Frunze, 1976. 19 s.

10. Nuller Yu.L. Trevoga i ee terapiya // Psikhiatriya i psikhofarmakoterapiya. 2002. T. 4. № 2. S. 46-48.

11. Komissarova Ya.V. Metodicheskie aspekty psikhofiziologicheskogoissledovaniya s primeneniem poligrafa // Rossiiskii sud'ya. 2006. № 2.

12. Molchanov A.Yu. Obshchaya teoriya poligrafnykh proverok. M., 2012.

13. Molchanov A.Yu. Atlas poligramm. M.: Indigo, 2007.

14. Piz A. Yazyk zhestov / Per. s angl. Voronezh: NPO «MODEK, 1992.

15. Filonov L.B. Psikhologicheskie sposoby vyyavleniya skryvaemogo obstoyatel'stva. M., 1979.

16. Kholodnyi Yu.I. Opros s ispol'zovaniem poligrafa i ego estestvenno-nauchnye osnovy // Vestnik kriminalistiki / Otv. red. A.G. Filippov. Vyp. 1(13) i 2(14). M., 2005.

17. Tselibeev B.A. Psikhicheskie narusheniya pri somaticheskikh zabolevaniyakh. M.: Meditsina, 1972. 279 s.

18. Yung K.Yu. Psikhologicheskie tipy. M.: Universitetskaya kniga, AST, 1998. 716 s.

19. Yurov I.E. Panicheskie rasstroistva u lits molodogo vozrasta: kliniko-psikhol., gemodinam. i patobiokhim. aspekty: Avtoref. dis. ... kand. med. nauk. M., 2000.

20. Yalov A.M. Koping-povedenie i mekhanizmy psikhologicheskoi zashchity u bol'nykh nevrozami // Obozrenie psikhiatrii i med. psikhologii im. V.M. Bekhtereva. 1996. № 3-4. S. 35-38. 